Original research article

\title{
Cold atmospheric pressure plasma jet modulates Candida albicans virulence traits
}

\author{
Aline Chiodi Borges ${ }^{\mathrm{a}}$, Thalita Mayumi Castaldelli Nishime ${ }^{\mathrm{b}}$, Konstantin Georgiev Kostov ${ }^{\mathrm{b}}$, \\ Gabriela de Morais Gouvêa Lima ${ }^{\mathrm{a}}$, Aline Vidal Lacerda Gontijo, ${ }^{\mathrm{a}, \mathrm{c}}$, \\ Juliana Nóbrega Martins Marchesotti de Carvalho ${ }^{\mathrm{a}}$, Roberto Yzumi Honda ${ }^{\mathrm{b}}$, \\ Cristiane Yumi Koga-Ito, ${ }^{\text {a, }}$ \\ a Department of Environmental Engineering and Oral Biopathology Graduate Program, São Paulo State University (UNESP), Institute of Science and Technology, São José \\ dos Campos, SP, Brazil \\ b Department of Physics and Chemistry, São Paulo State University (UNESP), Faculty of Engineering, Guaratinguetá, SP, Brazil \\ ${ }^{c}$ Departament of Biosciences and Technology of Bioactive Products. Institute of Biology, University of Campinas, SP, Brazil
}

\section{A R T I C L E I N F O}

\section{Keywords:}

Plasma

Antifungal

Candida albicans

Biofilms

Virulence

Cytotoxicity

\begin{abstract}
A B S T R A C T
Purpose: The goal of this study was to analyze the effects of cold atmospheric pressure plasma jet operated with Helium (He-CAPPJ) on C. albicans virulence traits and biofilms. The study also aimed to evaluate the cytotoxicity of He-CAPPJ to fibroblasts.

Methods: The effective operational parameters of He-CAPPJ against C. albicans SC 5314 were determined. Subinhibitory times of exposure were used to evaluate the effect of He-CAPPJ on morphogenesis (yeast-hyphae transition), adherence to epithelial cells, and exoenzymes production. Cytotoxicity to Vero cells was also assessed by MTT assay.

Results: A promising effect of He-CAPPJ on morphogenesis was observed, with an almost 40 times reduction of the filamentation rate comparing to the non-exposed group. He-CAPPJ was able to reduce $C$. albicans adherence and to decrease fungal biofilm viability. No effect on exoenzymes production was observed.

Conclusion: He-CAPPJ was able to attenuate fungal adherence and morphogenesis with low cytotoxicity to fibroblasts. Therefore, He-CAPPJ has potential to be applied as an adjuvant in the treatment of C. albicans superficial infections.
\end{abstract}

\section{Introduction}

Candida albicans is a commensal fungal species that colonizes several parts of the human body. However, under the occurrence of predisposing conditions, C. albicans can express opportunistic features, causing candidiasis $[1,2]$. Infections caused by Candida can range from superficial mucosal manifestations to life-threatening conditions [3]. Mortality rates can be as high as $50 \%$ among immunocompromised patients with systemic infection $[2,4,5]$.

The incidence of candidal infections depends on a complex interplay between fungal virulence factors and host's immune system [6]. C. albicans expresses several virulence traits, such as host recognition system, production of aspartyl proteases and phospholipases, and morphogenesis [6]. Moreover, C. albicans shows high capacity to adhere and to form biofilm on biotic and abiotic surfaces. These features contribute to colonization and infection [3].
Additionally, the ability of $C$. albicans to develop resistance against antifungals is remarkable $[1,2]$. Although azoles and polyenes are drugs of choice for the treatment of these infections, they are not always effective $[7,8]$. Besides, other adverse effects may occur, such as toxicity and interactions with other drugs [9], limiting the number of therapeutic alternatives. For this reason, the search for new antifungal therapies is of utmost importance.

Cold atmospheric pressure plasma (CAPP) has emerged as a promising technology in recent years. Due to their low operational cost, absence of residual and toxic emissions and operation at room temperature, cold plasmas have drawn much attention for biomedical applications [10-12]. Among different atmospheric plasma sources, special interest has been driven to cold atmospheric pressure plasma jets (CAPPJs), since plasma plumes can be obtained in open space instead of confined volumes [13]. The plasma plume propagates into the surrounding environment and interacts with air molecules creating

\footnotetext{
* Corresponding author.

E-mail address: cristiane@ict.unesp.br (C. Yumi Koga-Ito).
} 
reactive oxygen and nitrogen species (RONS), such as ozone, atomic oxygen, superoxide, peroxide, hydroxyl radicals, nitric oxide, and nitrogen dioxide [14]. These reactive species can affect the cell membrane integrity and interact with intracellular molecules, such as DNA and proteins, resulting in the inhibition of cell growth [15-17].

CAPPJs show promising biomedical applications, such as microbial inactivation [18-20], decontamination of medical equipment [21-23], blood coagulation [24], wound healing [25-27], and apoptosis of cancer cells $[24,28]$.

Previous studies reported the promising effect of APPJ operating with argon (Ar) or Helium (He) against C. albicans [29,30]. According to these previous reports, a mean period of $300 \mathrm{~s}$ of plasma exposure was needed to affect $C$. albicans viability in suspensions and biofilms $[20,30]$. However, previous studies on cytotoxicity to mammalian cells focused in short period treatment $(30 \mathrm{~s})$ and reported no mutagenic potential [31]. Thus, the aim of the present study was twofold. First, this study investigated the effects of shorter periods of exposures on $C$. albicans virulence traits (adherence to epithelial cells, exoenzymes production, and morphogenesis). Additionally, it aimed to evaluate the cytotoxic effects of longer exposures to CAPPJ on mammalian cells.

\section{Materials and methods}

\subsection{Plasma Source}

The experimental setup used in this study was described previously [32]. The device consists of a 2.3-mm-diameter copper rod connected to a Minipuls4 AC power supply (GBS Elektronik GmbH, Germany). The rod was inserted into a quartz tube (inner diameter of $2.6 \mathrm{~mm}$ and outer diameter of $6.0 \mathrm{~mm}$ ) with its bottom end closed. The quartz tube was placed on the axis of a syringe-like enclosure made of Delrin which terminated with a $2 \mathrm{~cm}$ long, $1.5 \mathrm{~mm}$ inner diameter nozzle. The plasma was generated inside the Delrin enclosure (around the high-voltage electrode) and driven into the surrounding air outside the nozzle by gas flow.

The system was fed with Helium (He) 99.5\% purity at a flow rate of 2.0 standard liters per minute (SLM). With this gas flow rate and a mean discharge power of $1.8 \mathrm{~W}$, the plasma jet had a length of about $2.5 \mathrm{~cm}$. The distance between the nozzle and the sample's surface was kept fixed at $1.5 \mathrm{~cm}$ in all experiments.

The characteristic emission lines of the plasma plume were investigated by an optical emission spectrometer (Andor Technology Shamrock 303i), as reported in Kostov et al. [32]. The spectrum was dominated by excited $\mathrm{N}_{2}$ and $\mathrm{N}_{2}{ }^{+}$emission lines. Some He lines was also observed and the presence of ROS was confirmed by a peak of O I at $777 \mathrm{~nm}$.

\subsection{Microorganism}

C. albicans SC 5314, a human clinical isolate with high ability to grow in invasive hyphal form, was used in this study. The strain was stored in Brain and Heart Infusion (BHI) broth with $20 \%$ of glycerol at $-80^{\circ} \mathrm{C}$ until use. After defrosting, C. albicans cells were grown in Sabouraud dextrose agar (SD) at $37^{\circ} \mathrm{C}$ for $24 \mathrm{~h}$. After this period, cells were scraped from agar and suspended in physiologic solution $(\mathrm{NaCl}$ $0.9 \%)$. Standardized fungal suspensions were obtained using a spectrophotometer.

\subsection{Determination of effective period of exposure}

Evaluation of He-CAPPJ effects on C. albicans suspension was performed to determine the parameters for antifungal effect. Based on the methodology proposed by Boekema et al. [33], aliquots of $150 \mu \mathrm{l}$ of standardized cell suspensions $\left(7 \times 10^{6}\right.$ cells ml $\left.{ }^{-1}\right)$ were added to 96 well plates with intervals of one column and one line. Thus, plasma did not reach adjacent wells, avoiding cumulative effect. After exposure to
He-CAPPJ for 30, 60 and $90 \mathrm{~s}$, suspensions were ten-fold diluted and plated on SD agar. After the incubation for $48 \mathrm{~h}\left(37^{\circ} \mathrm{C}\right), \mathrm{CFU} \mathrm{ml} \mathrm{m}^{-1}$ values were determined. Cell suspensions exposed to He flow (without plasma ignition) was used as the non-treated group. The experiments were made in triplicate on three different occasions $(n=9)$.

\subsection{Effect of He-CAPPJ on C. albicans virulence traits}

The periods of exposure that resulted in fungal count reduction lower than 1-log were considered sub-inhibitory. Based on the results obtained for He-CAPPJ activity, exposures of 30 and $60 \mathrm{~s}$ were adopted to evaluate the effects on $C$. albicans virulence traits (morphogenesis, adhesion to epithelial cells and exoenzyme production).

\subsubsection{Effect on fungal adherence to epithelial cells}

Oral epithelial cells were obtained from healthy volunteers after the approval of the Local Ethic Committee (CEP 698.119). The julgal mucosa was scraped with sterile swabs. According to Etgeton et al. [34], the epithelial cells were washed three times in PBS (phosphate-buffered saline) and centrifuged for $5 \mathrm{~min}(280 \mathrm{~g})$.

Aliquots of $450 \mu \mathrm{l}$ of the epithelial cell suspension $\left(10^{5}\right.$ cells $\left.\mathrm{ml}^{-1}\right)$ were added to $450 \mu \mathrm{l}$ of $C$. albicans suspension $\left(10^{5}\right.$ cells $\left.\mathrm{ml}^{-1}\right)$ previously exposed to He-APPJ for 30 and $60 \mathrm{~s}$. After incubation for $1 \mathrm{~h}$ at $37^{\circ} \mathrm{C}(70 \mathrm{rpm})$, suspensions were washed five times with PBS to remove non-adhered fungal cells. The cells were heat fixed on microscopy slides and stained with violet crystal (1 min). Differential staining using Papanicolaou technique was performed. The number of $C$. albicans adhered to 25 epithelial cells was determined by optical microscopy at $400 \times$ magnification. The experiment was repeated 3 times on different occasions $(n=75)$. Overlapped or folded cells were excluded. The results were compared to the non-treated group.

\subsubsection{Effects on morphogenesis (yeast to hyphae transition)}

An aliquot of $150 \mu$ of fungal standardized suspension $\left(10^{6}\right.$ cells $\mathrm{ml}^{-1}$ ) was exposed to He-CAPPJ for 30 and $60 \mathrm{~s}$. Then, $150 \mu \mathrm{l}$ of RPMI 1640 medium (supplemented with MOPS; pH 7.0), 2 times concentrated, was added to the fungal suspension. After incubation for $4 \mathrm{~h}$ $\left(37^{\circ} \mathrm{C}\right)$, the number of cells in yeast or hyphae forms was determined using a hemocytometer. Based on these counts, the number of yeast and hyphae per $\mathrm{ml}$ was calculated. In order to evaluate the possible late effects of He-CAPPJ on C. albicans morphogenesis, the percentage of filamentation was also evaluated after $24 \mathrm{~h}$ of incubation at $37^{\circ} \mathrm{C}$.

All experiments were made in triplicate on three different occasions $(\mathrm{n}=9)$. The percentage of filamentation was determined according to the following formula and compared between treated and non-treated groups:

Filamentation $(\%)=\frac{\text { number of hyphae } \times 100}{\text { number of hyphae }+ \text { yeast }}$

\subsubsection{Effect on the production of exoenzymes}

To evaluate the effect of He-CAPPJ on the production of protease and phospholipase, standardized fungal suspensions $\left(10^{6}\right.$ cells $\left.\mathrm{ml}^{-1}\right)$ were exposed to He-CAPPJ for 30 and $60 \mathrm{~s}$. Then, $2 \mu 1$ of the treated suspension were inoculated on phospholipase agar, according to Polak [35]. Protease agar plates were also inoculated under the same conditions [36]. Agar plates were incubated for 5 days $\left(37^{\circ} \mathrm{C}\right)$ and the results were expressed by $\mathrm{Pz}$ values, according to Price et al. [37]. Pz values were classified as follows, for both phospholipase and protease tests [38]: negative $(\mathrm{Pz}=1)$, low producers ( $\mathrm{Pz}: 0.75-0.9)$, moderate producers (Pz: 0.51-0.74) and high producers (Pz: 0.35-0.5). The experiments were made in triplicate on three different occasions $(n=9)$.

\subsection{Effect of He-CAPPJ on biofilms of C. albicans}

Biofilms of C. albicans were formed at the bottom of 96-well plates, 
by adding $200 \mu$ of RPMI 1640 medium (buffered to $\mathrm{pH} 7.0$ with MOPS and supplemented with $2 \%$ glucose) and $10 \mu \mathrm{l}$ of cell suspension $\left(10^{4}\right.$ cells/well). For the adherence phase, plates were incubated at $37{ }^{\circ} \mathrm{C}$ for $90 \mathrm{~min}(80 \mathrm{rpm})$. Non-adherent cells were then recovered by washing the wells with physiologic solution $(\mathrm{NaCl} 0.9 \%)$ and the culture medium was refreshed. After $24 \mathrm{~h}$ of incubation $\left(37^{\circ} \mathrm{C}\right)$, biofilms were washed with physiologic solution $(\mathrm{NaCl} 0.9 \%$ ) and were exposed to HeCAPPJ for 1, 2.5, 5, and $7.5 \mathrm{~min}$. Biofilms were disrupted by scraping to determine cell viability by CFU counting. The non-treated group was composed of biofilms exposed to He flow without plasma ignition. The experiments were made in triplicate on three different occasions ( $\mathrm{n}=$ 9).

Biofilms exposed to He-CAPPJ or He flow were also evaluated by scanning electron microscopy in order to observe morphologic alterations. For this purpose, biofilms were fixed with $2 \%$ glutaraldehyde solution for $48 \mathrm{~h}$. Biofilms were washed with physiologic solution $(\mathrm{NaCl}$ $0.9 \%$ ) and exposed to $70 \%$ and $95 \%$ ethanol for $10 \mathrm{~min}$ and $100 \%$ ethanol for $20 \mathrm{~min}$. After drying at $28^{\circ} \mathrm{C}$ for $48 \mathrm{~h}$, biofilms were coated with a thin gold layer (Emitech SC7620) and observed using an INSPECT S50 Scanning Electron Microscope.

\subsection{Evaluation of He-CAPPJ cytotoxicity}

Cytotoxicity tests were performed to evaluate the effects of He-APPJ at effective antifungal parameters (suspension and biofilm conditions). Vero cells were grown at $37^{\circ} \mathrm{C}$, in an atmosphere of $95 \%$ air and $5 \%$ $\mathrm{CO}_{2}$ in Dulbecco's Modified Eagle's medium (DMEM) supplemented with $10 \%$ of inactivated fetal bovine serum, $100 \mathrm{IU} \mathrm{ml}^{-1}$ of penicillin, and $100 \mu \mathrm{g} \mathrm{ml}^{-1}$ of streptomycin. The cells were seeded at a density of $6 \times 10^{4} /$ well in a 96-well microplate with intervals of one column and one line. The plates were then incubated for $24 \mathrm{~h}$ at $37^{\circ} \mathrm{C}$ to promote cell attachment to the plate. After this period, the culture medium was removed and $30 \mu \mathrm{l}$ of Hanks' Balanced Salt Solution at pH 7.4 with $10 \mathrm{mM}$ 3-(N-morpholino)propanesulfonic acid (HBSS-MOPS) were added to each well. The cells were exposed to plasma for $30,60,150$, and $300 \mathrm{~s}$.

The cell viability was evaluated immediately after plasma jet exposure and after 24 and $48 \mathrm{~h}$ of incubation in culture medium. The $3-$ (4,5-Dimethylthiazol-2-yl)-2,5-diphenyl tetrazolium bromide (MTT) assay was performed as described by Mosmann [39], with slight modifications. A volume of $100 \mu \mathrm{l}$ of fresh HBSS-MOPS/well containing $0.5 \mathrm{mg} \mathrm{ml}^{-1}$ MTT was added to the well and cultivated for another $3 \mathrm{~h}$ in the cell incubator. The MTT solution was replaced by DMSO to dissolve the formazan crystals. The values of the MTT-assay were measured using a microplate reader at $570 \mathrm{~nm}$ (Biotek Synergy ${ }^{\mathrm{Tm}} \mathrm{HT}$, Winooski, VT, EUA). The percentage of cell viability was obtained considering the non-treated cells (exposed to He flow) as 100\%. All experiments were performed in triplicate and repeated twice $(n=6)$.

The cytotoxicity of nystatin $(100,000 \mathrm{UI})$ and chlorhexidine digluconate $(0.12 \%)$ after exposition for $30,60,150$ and $300 \mathrm{~s}$ was also investigated.

\subsection{In vitro micronucleus assay}

The adopted protocol was based on the OECD Guidelines for Testing of Chemicals [40] and Andrighetti-Fröhner et al. [41]. Vero cells were cultivated and $10^{4}$ cells were transferred to each well of 96-well plates. Plates were incubated for $24 \mathrm{~h}\left(37^{\circ} \mathrm{C} ; 5 \% \mathrm{CO}_{2}\right)$. After this period, the culture medium was removed and $30 \mu \mathrm{l}$ of Hanks' Balanced Salt Solution (HBSS-MOPS) were added to each well. The cells were exposed to He-CAPPJ for 30 and $60 \mathrm{~s}$.

After the He-CAPPJ treatment, culture medium containing Cytochalasin B $\left(3 \mu \mathrm{g} \mathrm{ml}^{-1}\right)$ was added to each well. After $18 \mathrm{~h}$ of incubation, the culture medium was removed and cells were washed with PBS (phosphate-buffered saline). The cells were fixed in paraformaldehyde $4 \%$ solution and subsequently stained with 4', 6- diamidino-2-phenylindole (DAPI; Sigma-Aldrich). Using a fluorescent microscope $(200 \times), 1000$ binucleated cells were analyzed for the presence of micronucleus. The experiment was performed in duplicate.

\subsection{Statistical analyses}

Data were analyzed by GraphPad Prism 6 (GraphPad Software Inc.). The D'Agostino \& Pearson normality test was applied in order to evaluate the data distribution. The Kruskal-Wallis test and Dunn's Multiple Comparison post hoc test were used in order to analyze the effect of HeCAPPJ on planktonic cells and biofilms and its ability to reduce the adherence of $C$. albicans to buccal epithelial cells. Yeast-hyphae transition results were analyzed by One-way ANOVA and Dunnet's post hoc test. The level of significance was fixed at $5 \%$.

\section{Results}

\subsection{Effect of He-CAPPJ on planktonic C. albicans cells and virulence traits}

A significant reduction of fungal viable cells in suspension was observed after exposure to He-CAPPJ for 60 and $90 \mathrm{~s}$. After $90 \mathrm{~s}$, more than $1-\log$ reduction in viable cells counts was observed $(\mathrm{p}<0.001$; Kruskal-Wallis/Dunn) as shown in Fig. 1.

\subsubsection{Effect on fungal adherence to epithelial cells}

He-CAPPJ was able to reduce the fungal adhesion to epithelial cells ( $\mathrm{p}=0.0001$; Kruskal-Wallis/ Dunn) as shown in Table 1 . The median number of fungal cells adhered per epithelial cell was 3 in the nontreated group. The median number of fungal cell adhered to epithelial cells decreased to 2 and to 1 after $30 \mathrm{~s}$ and $60 \mathrm{~s}$ exposure to He-CAPPJ, respectively.

\subsubsection{Effects on morphogenesis (yeast to hyphae transition)}

After $4 \mathrm{~h}$ of incubation, non-exposed $C$. albicans showed a mean percentage of $38 \%$ of cells in hyphae form. This percentage was reduced to $7 \%$ and $0.9 \%$ after 30 and $60 \mathrm{~s}$ of exposure to He-CAPPJ, respectively (Fig. 2). Thus, plasma jet treatment during 30 and $60 \mathrm{~s}$ caused a significant reduction in filamentation percentage compared to the nontreated group after $4 \mathrm{~h}$ of incubation $(\mathrm{p}<0.001$; ANOVA/Dunnet's post hoc test).

In order to evaluate long-term effects, the cells were analyzed after $24 \mathrm{~h}$ of incubation. Results showed that the modulating effect of HeCAPPJ was maintained after this period (Fig. 2). Mean filamentation percentages observed for samples exposed to He-CAPPJ for 30 and $60 \mathrm{~s}$ were $8.8 \%$ and $6.2 \%$, respectively. These values were significantly lower comparing to the non-treated group $(16 \%)$ (p $<0.0001$; ANOVA/

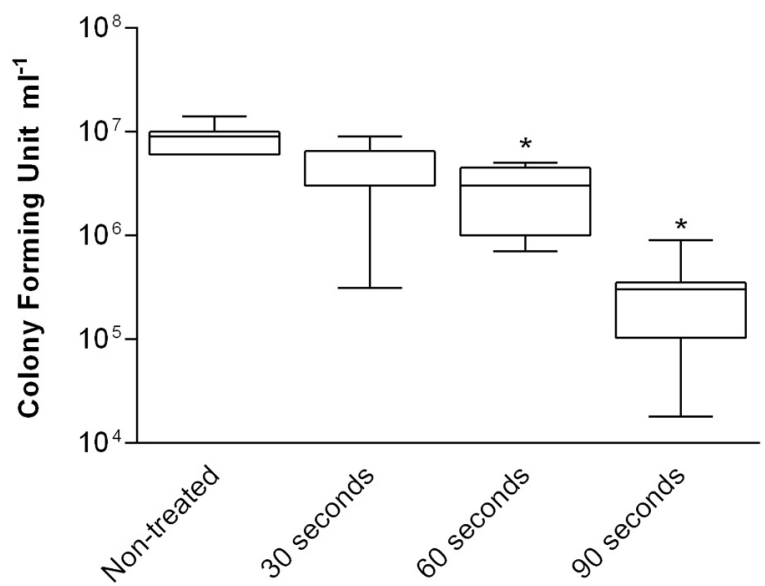

Fig. 1. Counts of C. albicans SC 5314, expressed as values of colony forming units per milliliter (median and interquartile ranges), obtained for suspensions exposed to He-APPJ (30, 60 and $90 \mathrm{~s}$ ) and non-treated group. *Statistically significant differences $(\mathrm{n}=9)$. 
Table 1

Median and interquartile range of $C$. albicans (non-treated or exposed to plasma for 30 and $60 \mathrm{~s}$ ) adhered to epithelial cells.

\begin{tabular}{llll}
\hline & Non-treated & $30 \mathrm{~s}$ & $60 \mathrm{~s}$ \\
\hline $25 \%$ Percentile & 2 & 1 & 1 \\
Median & 3 & 2 & 1 \\
$75 \%$ Percentile & 4 & 2 & 2 \\
p value $^{\mathrm{a}}$ & & 0.001 & 0.0001 \\
\hline
\end{tabular}

${ }^{\text {a }}$ Compared to non-treated group. Kuskal-Wallis/Dunn.

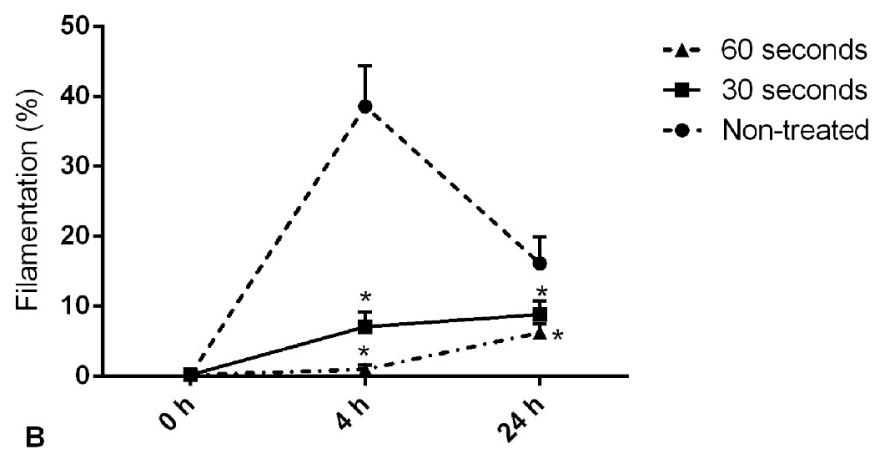

Fig. 2. Percentage of filamentation of $C$. albicans SC 5314 (mean \pm SD) at baseline, 4 and $24 \mathrm{~h}$ after exposure to APPJ. *Statistically significant differences $(\mathrm{n}=9)$.

Dunnet's post hoc test).

\subsubsection{Effect on the production of exoenzymes}

The median $\mathrm{Pz}$ value for phospholipase activity observed for nontreated group was 0.69 (interquartile range: $0.58 ; 0.70$ ). The median $\mathrm{Pz}$ value after exposure to He-CAPPJ during $30 \mathrm{~s}$ and $60 \mathrm{~s}$ was 0.66 (interquartile range: $0.60 ; 0.66$ ) and 0.62 (interquartile range: $0.62 ; 0.71$ ), respectively. No difference among the groups was observed. All groups were classified as moderate producers of phospholipase $(\mathrm{p}=0.51$; Kruskal-Wallis/Dunn's post hoc test).

Analyzing the protease activity, it was possible to observe that the $\mathrm{Pz}$ value (median) was 0.71 (interquartile range: $0.71 ; 0.71$ ) for nontreated group. After exposure to He-CAPPJ for 30 and $60 \mathrm{~s}$, the values remained the same (interquartile ranges: $0.71 ; 0.75$ and $0.71 ; 0.75$, respectively). No significant difference was observed among groups and both were classified as moderate producers of protease $(\mathrm{p}=0.59$; Kruskal-Wallis/Dunn's post hoc test).

\subsection{Effect of He-CAPPJ on C. albicans biofilms}

The viability of $C$. albicans biofilms was significantly reduced after 5 and $7.5 \mathrm{~min}$ of exposure to He-CAPPJ ( $\mathrm{p}<0.0001$; Kruskal-Wallis/ Dunn's post hoc test). Approximately 2-log reduction was observed after 7.5 min of exposure (Fig. 3). SEM images of fungal biofilms showed that He-CAPPJ affected the fungal cell structure (Fig. 4). The cells exposed only to gas flow showed no alterations in their morphology and the hyphae showed continuous and smooth surfaces. After He-CAPPJ exposure, the biofilms lost their typical morphological features and the hyphae surfaces became rough and shrunk.

\subsection{Cytotoxicity of He-CAPPJ}

The viability of Vero cells after plasma jet exposure is shown in Fig. 5. Immediately after $30 \mathrm{~s}$ of exposure to He-CAPPJ, the viability was greater than $60 \%$ and the cells demonstrated ability of regeneration 24 and $48 \mathrm{~h}$ after the treatment (almost 100\% of viability). After $60 \mathrm{~s}$ of exposure, more than $60 \%$ of the cells were viable. The percentage of cell viability was the same $48 \mathrm{~h}$ after plasma exposure. The cell viability decreased to almost $2 \%$ after exposure to He-CAPPJ for $150 \mathrm{~s} \mathrm{(2.5 \textrm {min } )}$

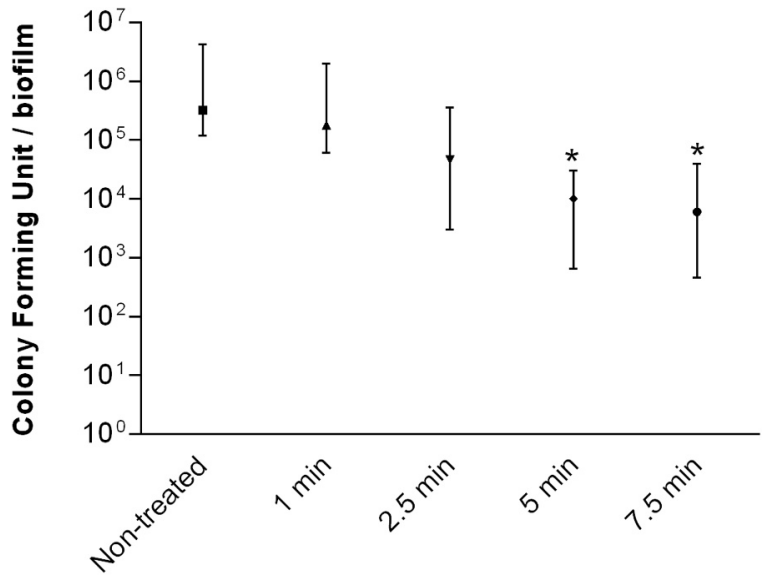

Fig. 3. Counts of viable cells in C. albicans SC 5314 biofilms (median with range), expressed as colony forming units, in non-treated group and exposed to He-APPJ for 1, 2.5, 5 and $7.5 \mathrm{~min}$ *Statistically significant differences $(\mathrm{n}=9)$.

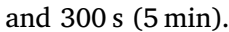

Similar cytotoxic effects were observed for nystatin and plasma after 30 and $60 \mathrm{~s}$ of exposure ( $\mathrm{p}>0.05$; Bonferroni's Test). After $24 \mathrm{~h}$ from exposure, the number of viable cells was significantly higher in the plasma-treated group than in the nystatin group ( $p<0.05$ and $\mathrm{p}<0.01$, respectively; Bonferroni's Test). After $48 \mathrm{~h}$ from exposure, plasma (30 s of exposure) and nystatin showed similar toxicity. Nystatin was less cytotoxic than the plasma jet after longer time exposures (150 and $300 \mathrm{~s}$ ). The cell viability was lower than $50 \%$ after the long treatments with both plasma and nystatin, suggesting toxicity.

Chlorhexidine digluconate was more toxic than the He-CAPPJ after exposure for 30 and $60 \mathrm{~s}$.

\subsection{In vitro micronucleus assay}

The frequency of micronuclei in the He-CAPPJ treated group was similar to non-treated group, suggesting absence of genotoxic effect. In non-treated group, $1.2 \pm 0.3 \%$ of binucleated cells presented micronuclei. In He-CAPPJ groups ( 30 and $60 \mathrm{~s}$ of exposure), $1.6 \pm 0.4$ and $1.9 \pm 0.5 \%$ of binucleated cells showed micronuclei, respectively.

\section{Discussion}

The effect of cold atmospheric pressure plasma jets on $C$. albicans has been previously described $[20,29,30]$. However, the effects of CAPPJ on C. albicans virulence factors have not been fully evaluated with only sparse reports on the reduction of exoenzymes production [42]. Considering that the occurrence of the disease depends directly on the expression of fungal virulence factors, the interference on these traits may contribute significantly to the infection control. Furthermore, in order to support future clinical applications, it is of utmost importance to evaluate the cytotoxicity of CAPPJ. Studies on this subject are scarce in the literature, in particular adopting the effective antimicrobial operational parameters. To our knowledge, this is the first study to evaluate the effects of He-CAPPJ on C. albicans adherence to epithelial cells, yeast-hyphae transition and the cytotoxicity and genotoxicity to Vero cells at effective operation conditions.

An extensive previous study was performed in order to determine the physical parameters of the He-CAPPJ device (exposure time, gas flow, voltage amplitude and frequency, power) for obtaining inhibitory effects on C. albicans [32]. In order to enable the evaluation of HeCAPPJ effects on C. albicans virulence traits, sub-inhibitory parameters were determined.

Previous studies reported that the antimicrobial activity of plasma jets can differ according to the liquid component of the suspension $[33,43]$. Acidic conditions seem to favor the effect of plasma jets, 


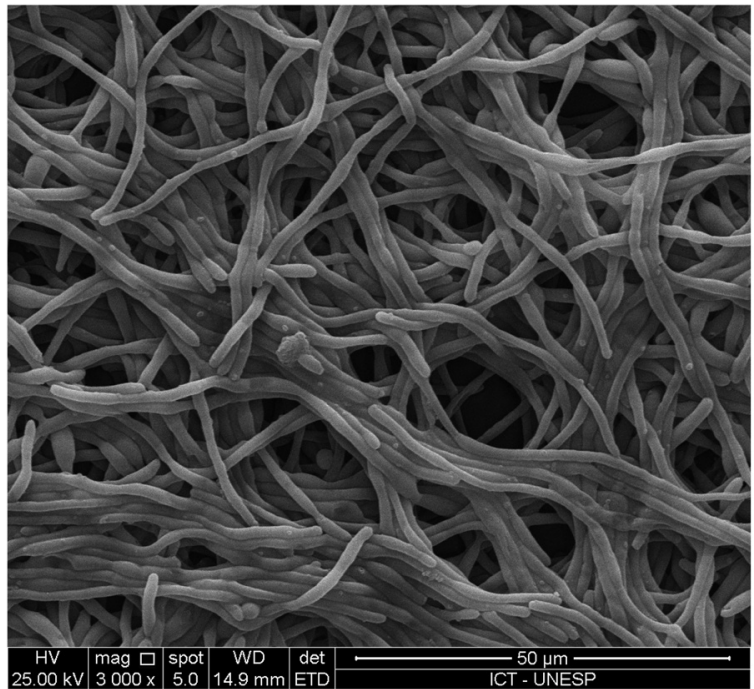

A

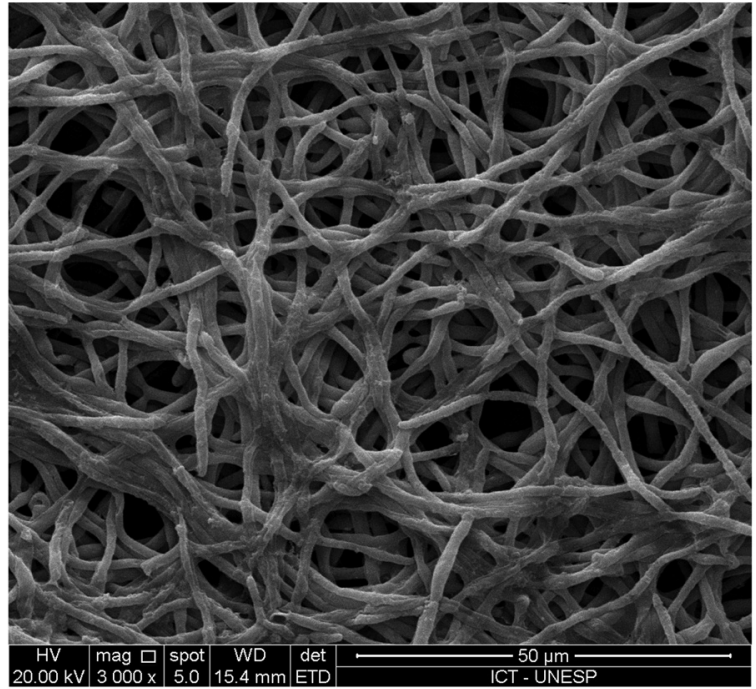

C

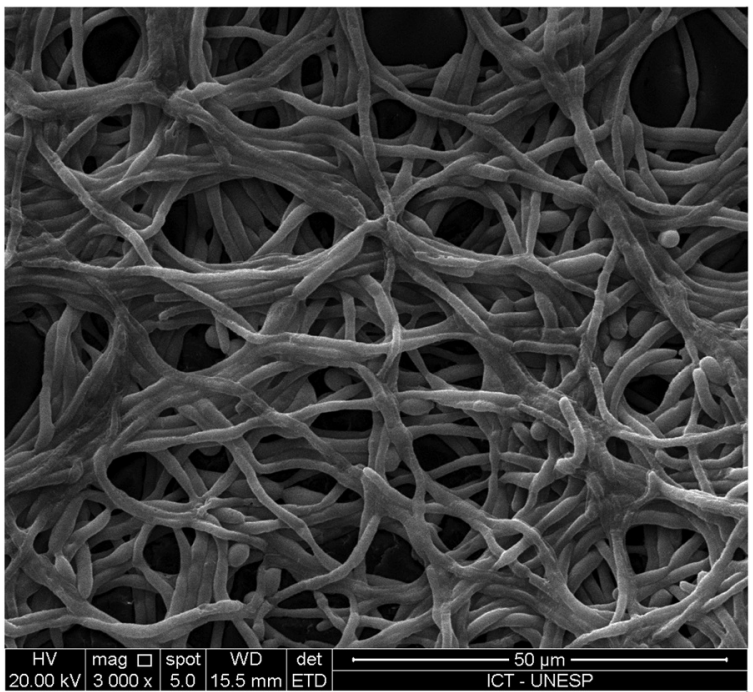

B

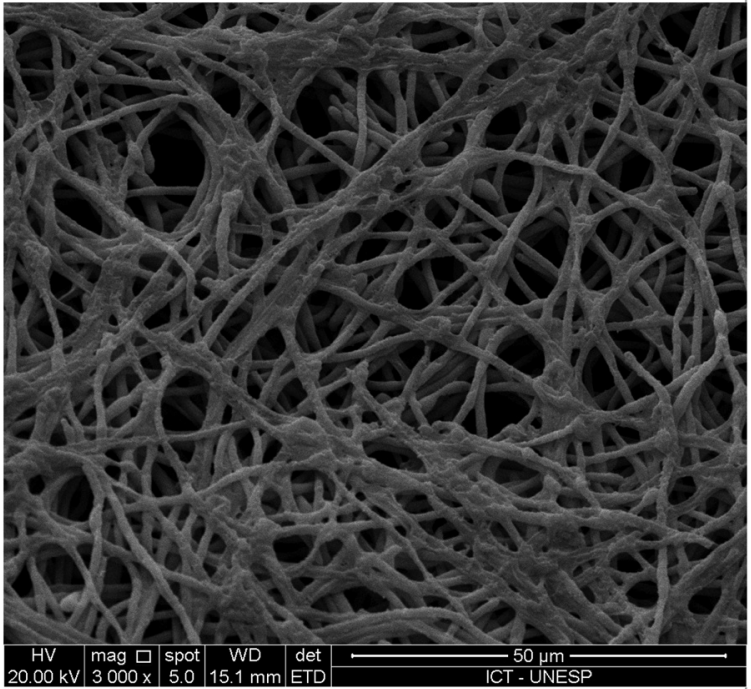

$\mathrm{D}$

Fig. 4. Scanning electron microscopy of C. albicans SC 5314 biofilms exposed or not to He-APPJ. (A) non-treated, (B) Exposed to He-APPJ for 2.5 min, (C) 5 min, and (D) 7.5 min.

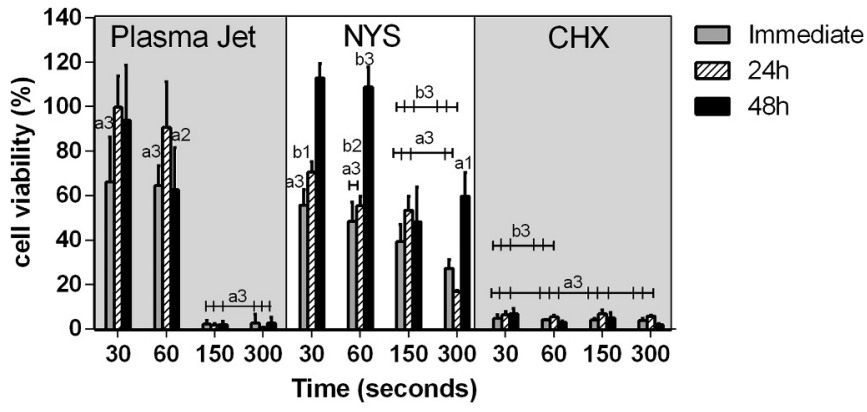

Fig. 5. Percentage of Vero cells viability (\%; means and standard deviation) after exposure to He-CAPPJ, nystatin at 100,000 UI (NYS) and chlorhexidine digluconate at $0.12 \%$ (CHX) for 30, 60, 150 and $300 \mathrm{~s}$. Cell viability was evaluated immediately after exposure and after 24 and $48 \mathrm{~h}$. The letter "a" represents statistical difference from the non-treated group (a1: $\mathrm{p}<0.05$; $\mathrm{a} 2 \mathrm{p}<0.01$; $\mathrm{a}$ : $\mathrm{p}<0.001$ ). The letter "b" represents statistical difference from the He-CAPPJ (b1: $\mathrm{p}<0.05$; b2: $\mathrm{p}<0.01$; b3: $\mathrm{p}<0.001$ ). One-way analysis of variance and Bonferroni's Multiple Comparison Test were used ( $\mathrm{n}=$ 6).

probably due to the higher equilibrium and solubility of oxygen and nitrogen radicals at this condition [29]. A similar effect was observed using argon plasma [33]. For this reason, in this study, a physiologic solution $(\mathrm{NaCl} 0.9 \%) \mathrm{pH} 5.8$, was chosen for the tests. We observed that the viability of $C$. albicans in suspension was significantly reduced for exposures to He-CAPPJ longer than $60 \mathrm{~s}$. Under these conditions, the jet effluent interacts with the liquid surface generating $\mathrm{OH}$ and $\mathrm{H}_{2} \mathrm{O}_{2}$ due to the electron impact dissociation of $\mathrm{H}_{2} \mathrm{O}[44,45]$.

Candida albicans SC 5314 was chosen for this study due to its remarkable capacity to grow in invasive hyphal form when compared to other strains $[46,47]$. Additionally, it has been isolated from human infection.

The results showed that He-CAPPJ can reduce the adherence of $C$. albicans to epithelial cells after $30 \mathrm{~s}$ and $60 \mathrm{~s}$ of exposure. The ability of He-CAPPJ to avoid C. albicans adhesion can impair the first step of biofilm formation, as well as the colonization and survival in the host. Adhesion requires interaction between epithelial receptors and fungal adhesins [48]. One possible hypothesis for the effect of He-CAPPJ on fungal adherence is that the RONS may have performed some activity on adhesins. Future studies on the effect of plasma jet on specific adhesins, such as Als (agglutinin-like sequence) or Hwp 1 (hyphal wall protein 1) could be useful to understand the exact molecular mechanisms of He-CAPPJ on fungal adherence.

After the adhesion phase, hyphal formation and enzymes secretion contribute to the invasion of the host tissue [48]. Filamentation is 
considered a critical virulence determinant for C. albicans [49]. Jacobsen et al. [50] suggested that targeting the morphological switch can be a promising therapeutic option. In this study, we found that He-CAPPJ could reduce significantly $C$. albicans yeast-hyphae transition. This is a promising observation since it has been experimentally demonstrated that blocking filamentation attenuates the in vivo virulence [51].

It is known that the interference on the filamentation process might be related to alteration in the fungal gene expression [52] or to environmental modifications such as temperature, $\mathrm{pH}$ and presence of serum $[53,54]$. Nadeem et al. [55] reported that low $\mathrm{pH}$ induces low filamentation. Hence, in order to avoid the influence of $\mathrm{pH}$, the treated fungal samples were cultivated into MOPS-buffered RPMI medium ( $\mathrm{pH}$ 7.0). Based on the results, we hypothesize that the observed phenomenon is related to the modulation of hypha-specific gene expression. However, further studies should be conducted to confirm this mechanism.

This study showed that the He-CAPPJ jet did not influence protease and phospholipase activity of $C$. albicans SC 5314. Conversely, RahimiVerki et al. [42] observed a reduction of enzymatic activity in C. albicans ATCC 10231 after exposure to a $\mathrm{He} / \mathrm{O}_{2}$ plasma jet for $90 \mathrm{~s}$. The contrast in the findings may be associated to significant differences in the plasma sources, $C$. albicans strains and volume of testing suspension between the studies. To our knowledge, there is no other study describing the effect of plasma jets on $C$. albicans enzymatic activity that could be used for further comparative analyses.

We found that He-CAPPJ could affect $C$. albicans SC 5314 biofilms from $5 \mathrm{~min}$ of exposure. These results are in accordance to a previous study that showed an anti-biofilm effect after $5 \mathrm{~min}$ when using CAPPJ operating with $\mathrm{Ar} / \mathrm{O}_{2}$ mixture [30].

Morphological cell changes observed by SEM analyses in this study were similar to those previously reported in [20]. The images of SEM showed that $C$. albicans SC 5314 forms a dense biofilm mostly constituted of a network of interlaced hyphae. Even with this complex structure, the biofilm was susceptible to plasma plume exposure. The alterations in cell structure are probably a product of the direct interaction of the cells and the reactive species produced by the plasma jet (nitric oxide, nitrogen dioxide, hydroxyl radicals, superoxide, ozone, and singlet oxygen) [56].

It is known that the considerable differences among the methodologies employed in the published studies (plasma sources, working gas, gas flow, power) can influence the antimicrobial outcomes. Ehlbeck et al. [57] reinforced the difficulty of interpretation of results due to the non-standardized methods used in different studies. It has been suggested that small variations in the set up may considerably influence the results. These evidences highlight the need of caution when comparing different studies and also reinforce the need of standardized methods for APPJ antimicrobial studies.

The evaluation of cytotoxicity assays showed that the periods of exposure that reduced pre-formed biofilm viability (150 and $300 \mathrm{~s}$ ) were toxic to Vero cells in vitro. These results suggest that the application of He-CAPPJ in this configuration and set of operational parameters for $C$. albicans biofilm control may have limitations. Interestingly, the reduction of the fungal cells in biofilm and the decrease of Vero cells viability after exposure to He-CAPPJ for 5 min were very similar. This finding can be related to the similarities between mammalian and fungal cells, since both are eukaryotic. Future studies using other protocols of application should be developed.

Notwithstanding, it is important to note that the results of cytotoxicity are meant for initial evaluation, considering that Vero cells are frequently used as a screening cytotoxicity assay. Considering that plasma jet will be applied to the mucosal surface in cases of candidiasis, future studies evaluating the effects of He-CAPPJ on human epithelial cells are needed.

Finally, we also observed moderate cell toxicity when Vero cells were exposed to He-CAPPJ for 30 and $60 \mathrm{~s}$. This moderate cell toxicity suggests acceptable tissue tolerability [58]. Interestingly, these shorter periods of plasma jet application can attenuate significantly fungal adherence and filamentation. Furthermore, the cells showed significant ability to regenerate 24 and $48 \mathrm{~h}$ after exposure to He-CAPPJ for $30 \mathrm{~s}$. These results are in accordance with a previous study [59] that showed low toxicity to normal human epithelial cells after exposure to a plasma jet operated with helium for $30 \mathrm{~s} 48 \mathrm{~h}$ after treatment.

The micronucleus assay showed no genotoxic effect of He-CAPPJ after 30 and $60 \mathrm{~s}$ of exposure. This assay verifies the presence of small nuclei, separate from the main nuclei of cells, produced during mitosis [40]. According to the Guideline for Testing Chemicals, the absence of micronuclei indicates that a chromosome aberration in cultured cells was not induced by the treatment. Recent studies also show that Argonplasma jet did not increase the number of micronuclei compared to untreated control [60] and confirm the lack of genotoxicity [61].

The results support the hypothesis that He-CAPPJ could be used as adjuvant for the treatment of candidiasis and indicate that protocols of APPJ for candidal infection should consider short exposures and multiple treatment sessions.

\section{Conclusions}

The current data showed the potential of He-CAPPJ in reducing the adherence to epithelial cells and yeast-hyphae transition in C. albicans with low cytotoxicity after short treatment times. The period of exposure to reduce candidal biofilm viability was cytotoxic to Vero cells. No genotoxicity of He-CAPPJ was detected.

\section{Funding}

This study was supported by São Paulo Research Foundation (FAPESP): Grants \#2016/07196-6 (CY Koga-Ito); \#2015/21989-6 (KG Kostov) and fellowships (AC Borges, \#2014/02354-7; AVL Gontijo, \#2014/09666; and GMG Lima, \#2015/03470-3).

\section{Conflict of interest}

The authors declare no conflict of interest.

\section{Ethical Statement}

Not applicable for this article.

\section{Authors' contributions}

Aline Chiodi Borges - Collected the data; Contributed data or analysis tools; Performed the analysis; Wrote the paper.

Thalita Mayumi Castaldelli Nishime - Collected the data; Contributed data or analysis tools; Performed the analysis; Wrote the paper.

Konstantin Georgiev Kostov - Conceived and designed the analysis; Performed the analysis; Wrote the paper.

Gabriela de Morais Gouvêa Lima - Performed the analysis; Contributed data or analysis tools.

Juliana Nóbrega Martins Marchesotti de Carvalho - Collected the data Aline Vidal Lacerda Gontijo - Performed the analysis; Contributed data or analysis tools.

Roberto Yzumi Honda - Conceived and designed the analysis; Performed the analysis.

Cristiane Yumi Koga-Ito - Conceived and designed the analysis; Performed the analysis; Wrote the paper.

\section{References}

[1] H. Tournu, P.V. Dijck, Candida biofilms and the host: models and new concepts for eradication, Int. J. Microbiol. 2012 (2012) 1-16.

[2] M. Polke, B. Hube, I.D. Jacobsen, S. Sima, G. Geoffrey Michael, Chapter three Candida survival strategies, Adv. Appl. Microbiol. 91 (2015) 139-235.

[3] C.J. Nobile, A.D. Johnson, Candida albicans biofilms and human disease, Annu. Rev. Microbiol. 69 (2015) 71-92. 
[4] S.D. Willger, S.L. Grim, E.L. Dolben, A. Shipunova, T.H. Hampton, H.G. Morrison, L.M. Filkins, G.A. O‘Toole, L.A. Moulton, A. Ashare, M.L. Sogin, D.A. Hogan, Characterization and quantification of the fungal microbiome in serial samples from individuals with cystic fibrosis, Microbiome 2 (2014) 1-15.

[5] E.O. Oyetola, F.J. Owotade, G.A. Agbelusi, O.A. Fatusi, A.A. Sanusi, Oral findings in chronic kidney disease: implications for management in developing countries, BMC Oral. Health 15 (2015) 1-8.

[6] S. Höfs, S. Mogavero, B. Hube, Interaction of Candida albicans with host cells: virulence factors, host defense, escape strategies, and the microbiota, J. Microbiol. 54 (2016) 149-169.

[7] M. Bondaryk, W. Kurzątkowski, M. Staniszewska, Antifungal agents commonly used in the superficial and mucosal candidiasis treatment: mode of action and resistence development, Postepy Dermatol Alergol. 5 (2013) 293-301.

[8] C. Garcia-Cuesta, M.G. Sarrion-Pérez, J.V. Bagán, Current treatment of oral candidiasis: a literature review, J. Clin. Exp. Dent. 6 (2014) e576-e582.

[9] J.S. Lewis, J.R. Graybill, Fungicidal versus fungistatic: what's in a word? Expert Opin. Pharmacother. 9 (2008) 927-935.

[10] K.-D. Weltmann, E. Kindel, T. von Woedtke, M. Hähnel, M. Stieber, R. Brandenburg, Atmospheric-pressure plasma sources: prospective tools for plasma medicine, Pure Appl. Chem. 82 (2010) 1223-1237.

[11] T. von Woedtke, S. Reuter, K. Masur, K.-D. Weltmann, Plasmas for medicine, Phys. Rep. 530 (2013) 291-320.

[12] O. Yardimci, P. Setlow, Plasma sterilization: opportunities and microbial assessment strategies in medical device manufacturing, IEEE Trans. Plasma Sci. 38 (2010) 973-981.

[13] M. Laroussi, T. Akan, Arc-free, atmospheric pressure cold plasma jets: a review, Plasma Process Polym. 4 (2007) 777-788.

[14] X. Lu, T. Ye, Y. Cao, Z. Sun, Q. Xiong, Z. Tang, Z. Xiong, J. Hu, Z. Jiang, Y. Pan, The roles of the various plasma agents in the inactivation of bacteria, J. Appl. Phys. 104 (2008) 053309.

[15] M. Laroussi, D.A. Mendis, M. Rosenberg, Plasma interaction with microbes, New J. Phys. 5 (2003) 41.1-41.10.

[16] J.-W. Lackmann, S. Schneider, E. Edengeiser, F. Jarzina, S. Brinckmann, E. Steinborn, M. Havenith, J. Benedikt, J.E. Bandow, Photons and particles emitted from cold atmospheric-pressure plasma inactivate bacteria and biomolecules independently and synergistically, J. R. Soc. Interface 10 (2013) (20130591).

[17] M. Alkawareek, G. Gorman, W. Grahan, B. Gilmore, Potencial cellular targets and bacterial efficacy of atmospheric pressure non-thermal plasma, Int. J. Antimicrob. Agents 43 (2014) 154-160.

[18] P.P. Sedghizadeh, M.-T. Chen, C. Schaudinn, A. Gorur, C. Jiang, Inactivation kinetics study of an atmospheric-pressure cold-plasma jet against pathogenic microorganisms, IEEE Trans. Plasma Sci. 40 (2012) 2879-2882.

[19] M.Y. Alkawareek, Q.T. Algwari, S.P. Gorman, W.G. Graham, D. O'Connell, B.F. Gilmore, Application of atmospheric pressure nonthermal plasma for the in vitro eradication of bacterial biofilms, FEMS Immunol. Med. Microbiol. 65 (2012) 381-384.

[20] Y. Sun, S. Yu, P. Sun, H. Wu, W. Zhu, W. Liu, J. Zhang, J. Fang, R. Li, Inactivation of Candida biofilms by non-thermal plasma and its enhancement for fungistatic effect of antifungal drugs, PLoS One 7 (2012) e40629.

[21] K.D. Weltmann, R. Brandenburg, T. von Woedtke, J. Ehlbeck, R. Foest, M. Stieber, E. Kindel, Antimicrobial treatment of heat sensitive products by miniaturized atmospheric pressure plasma jets (APPJs), J. Phys. D: Appl. Phys. 41 (2008) 194008.

[22] A. Mai-Prochnow, A.B. Murphy, K.M. McLean, M.G. Kong, K. Ostrikov, Atmospheric pressure plasmas: infection control and bacterial responses, Int. J. Antimicrob. Agents 43 (2014) 508-517.

[23] M.A. Sharkey, A. Chebbi, K.A. McDonnell, C. Staunton, D.P. Dowling, Evaluation of the sensitivity of bacterial and yeast cells to cold atmospheric plasma jet treatments, Biointerphases 10 (2015) 029507.

[24] G. Fridman, G. Friedman, A. Gutsol, A.B. Shekhter, V.N. Vasilets, A. Fridman, Applied plasma medicine, Plasma Process Polym. 5 (2008) 503-533.

[25] T. Nosenko, T. Shimizu, G.E. Morfill, Designing plasmas for chronic wound disinfection, New J. Phys. 11 (2009) 115013.

[26] G. Isbary, W. Stolz, T. Shimizu, R. Monetti, W. Bunk, H.-U. Schmidt, G.E. Morfill, T.G. Klämpfl, B. Steffes, H.M. Thomas, J. Heinlin, S. Karrer, M. Landthaler, J.L. Zimmermann, Cold atmospheric argon plasma treatment may accelerate wound healing in chronic wounds: results of an open retrospective randomized controlled study in vivo, Clin. Plasma Med. 1 (2013) 25-30.

[27] S. Bekeschus, A. Schmidt, K. Weltmann, Tv Woedtke, The plasma jet kINPen - a powerful tool for wound healing, Clin. Plasma Med. 4 (2016) 19-28.

[28] M.G. Kong, G. Kroesen, G. Morfill, T. Nosenko, T. Shimizu, Jv Dijk, J.L. Zimmermann, Plasma medicine: an introductory review, New J. Phys. 11 (2009) 115012.

[29] H. Yamazaki, T. Ohshima, Y. Tsubota, H. Yamaguchi, J.A. Jayawardena, Y. Nishimura, Microbicidal activities of low frequency atmospheric pressure plasma jets on oral pathogens, Dent. Mater. J. 30 (2011) 384-391.

[30] K. Fricke, I. Koban, H. Tresp, L. Jablonowski, K. Schröder, A. Kramer, K.D. Weltmann, T. von Woedtke, T. Kocher, Atmospheric pressure plasma: a highperformance tool for the efficient removal of biofilms, PLoS One 7 (2012) e42539.

[31] V. Boxhammer, Y.F. Li, J. Köritzer, T. Shimizu, T. Maisch, H.M. Thomas, J. Schlegel, G.E. Morfill, J.L. Zimmermann, Investigation of the mutagenic potential of cold atmospheric plasma at bactericidal dosages, Mutat. Res. 753 (2013) 23-28.

[32] K.G. Kostov, A.C. Borges, C.Y. Koga-Ito, T.M.C. Nishime, V. Prysiazhnyi, R.Y. Honda, Inactivation of Candida albicans by cold atmospheric pressure plasma jet, IEEE Trans. Plasma Sci. 43 (2015) 770-775.

[33] B. Boekema, F. Hofmann, Bv Ham, P. Bruggeman, E. Middelkoop, Antibacterial plasma at safe levels for skin cells, J. Phys. D: Appl. Phys. 46 (2013) 422001.

[34] S. Etgeton, F. Chassot, C. Boer, L. Donatti, T. Svidzinsky, M. Consolaro, Influência da co-agregação entre Candida albicans e Lactobacillus acidophilus na capacidade de adesão destes microrganismos às células epiteliais vaginais humanas, Acta Sci. Health Sci. 33 (2011) 1-8.

[35] A. Polak, Virulence of Candida albicans mutants, Mycoses 35 (1992) 9-16.

[36] S. Aoki, S. Ito-Kuwa, Y. Nakamura, T. Masuhara, Comparative pathogenicity of a wild-type strain and respiratory mutants of Candida albicans in mice, Zent. Bakteriol. 273 (1990) 332-343.

[37] M. Price, I. Wilkson, L. Gentry, Plate method for detection of phospholipase activity in Candida albicans, Sabouraudia 20 (1982) 7-14.

[38] A.S. Mattei, S.H. Alves, C.B. Severo, Ld.S. Guazzelli, Fd.M. Oliveira, L.C. Severo, Determination of germ tube, phospholipase, and proteinase production by bloodstream isolates of Candida albicans, Rev. Soc. Bras. Med. Trop. 46 (2013) 340-342.

[39] T. Mosmann, Rapid colorimetric assay for cellular growth and survival: application to proliferation and cytotoxicity assays, J. Immunol. Methods 65 (1983) 55-63.

[40] OECD, Test No. 487: In vitro Mammalian Cell Micronucleus Test, OECD Publishing, Paris, 2014.

[41] C. Andrighetti-Fröhner, J. Kratz, R. Antonio, T. Creczynski-Pasa, C. Barardi, C. Simões, In vitro testing for genotoxicity of violacein assessed by Comet and micronucleus assays, Mutat. Res. 603 (2006) 97-103.

[42] N. Rahimi-Verki, A. Shapoorzadeh, M. Razzaghi-Abyaneh, S.-M. Atyabi, M. ShamsGhahfarokhi, Z. Jahanshiri, M. Gholami-Shabani, Cold atmospheric plasma inhibits the growth of Candida albicans by affecting ergosterol biosynthesis and suppresses the fungal virulence factors in vitro, Photo. Photodyn. Ther. 13 (2016) 66-72.

[43] J.W. Lackmann, J.E. Bandow, Inctivation of microbes and macromolecules by atmospheric-pressure plasma jets, Appl. Microbiol. Biotechnol. 98 (2014) 6205-6213.

[44] S.A. Norberg, W. Tian, E. Johnsen, M.J. Kurshner, Atmospheric pressure plasma jets interacting with liquid covered tissue: touching and not touching the liquid, J. Phys. D: Appl. Phys. 47 (2014) 475203.

[45] K. Wende, P. Williams, J. Dalluge, W.V. Gaens, H. Aboubarkr, J. Bischof, Tv Woedtke, S.M. Goyal, K.-D. Weltmann, A. Bogaerts, K. Masur, P.J. Bruggeman, Identification of the biologically active liquid chemistry induced by a nonthermal atmospheric pressure plasma jet, Biointerphases 10 (2015) 029518.

[46] X. Hua, X. Yuan, B.M. Mitchell, M.C. Lorenz, D.M. O’Day, K.R. Wilhelmus, Morphogenic and genetic differences between Candida albicans strains are associated with keratomycosis virulence, Mol. Vis. 15 (2009) 1476-1484.

[47] M.P. Hirakawa, D.A. Martinez, S. Sakthikumar, M. Anderson, A. Berlin, S. Gujja, Q. Zeng, E. Zisson, J.M. Wang, J.M. Greenberg, J. Berman, R.J. Bennett, C.A. Cuomo, Genetic and phenotypic intra-species variation in Candida albicans, Genome Res. 25 (2014).

[48] D.L. Moyes, J.P. Richardson, J.R. Naglik, Candida albicans-epithelial interactions and pathogenicity mechanisms: scratching the surface, Virulence 6 (2015) 338-346.

[49] Y. Lu, C. Su, H. Liu, Candida albicans hyphal initiation and elongation, Trends Microbiol. 22 (2014) 707-714.

[50] I.D. Jacobsen, D. Wilson, B. Wächtler, S. Brunke, J.R. Naglik, B. Hube, Candida albicans dimorphism as a therapeutic target, Expert Rev. Anti Infect. Ther. 10 (2012) 85-93.

[51] S.P. Saville, A.L. Lazzell, A.P. Bryant, A. Fretzen, A. Monreal, E.O. Solberg, C. Monteagudo, J.L. Lopez-Ribot, G.T. Milne, Inhibition of filamentation can be used to treat disseminated Candidiasis, Antimicrob. Agents Chemother. 50 (2006) 3312-3316.

[52] H.M. Bandara, B. Cheung, R. Watt, L. Jin, L. Samaranayake, Secretory products of Escherichia coli biofilm modulate Candida biofilm formation and hyphal development, J. Investig. Clin. Dent. 4 (2013) 186-199.

[53] J. Shareck, A. Nantel, P. Belhumeur, Conjugated linoleic acid inhibits hyphal growth in Candida albicans by modulating Ras1p cellular levels and downregulating TEC1 expression, Eukariotic Cell. 10 (2011) 565-577.

[54] A. Wartenberg, J. Linde, R. Martin, M. Schreiner, F. Horn, I. Jacobsen, S. Jenull, T. Wolf, K. Kuchler, R. Guthke, O. Kurzai, A. Forche, C. d'Enfert, S. Brunke, B. Hube, Microevolution of Candida albicans in macrophages restores filamentation in a nonfilamentous mutant, PLoS Genet. 10 (2014) e1004824.

[55] S.G. Nadeem, A. Shafiq, S.T. Hakim, Y. Anjum, S.U. Kazm, Effect of growth media, $\mathrm{pH}$ and temperature on yeast to hyphal transition in Candida albicans, Open J. Med. Microbiol. 3 (2013) 185-192.

[56] J. Liebmann, J. Scherer, N. Bibinov, P. Rajasekaran, R. Kovacs, R. Gesche, P. Awakowicz, V. Kolb-Bachofen, Biological effects of nitric oxide generated by an atmospheric pressure gas-plasma on human skin cells, Nitric Oxide 24 (2011) 8-16.

[57] J. Ehlbeck, U. Schnabel, M. Polak, J. Winter, T. von Woedtke, R. Brandenburg, T. v.d. Hagen, K.D. Weltmann, Low temperature atmospheric pressure plasma sources for microbial decontamination, J. Phys. D: Appl. Phys. 44 (2011) 013002.

[58] R. Matthes, C. Bender, R. Schlüter, I. Koban, R. Bussiahn, S. Reuter, J. Lademann, K.-D. Weltmann, A. Kramer, Antimicrobial efficacy of two surface barrier discharges with air plasma against in vitro biofilms, PLoS One 8 (2013) e70462.

[59] R. Guerrero-Preston, T. Ogawa, M. Uemura, G. Shumulinsky, B.L. Valle, F. Pirini, R. Ravi, D. Sidransky, M. Keidar, B. Trink, Cold atmospheric plasma treatment selectively targets head and neck squamous cell carcinoma cells, Int. J. Mol. Med. 34 (2014) 941-946.

[60] K. Wende, S. Bekeschus, A. Schmidt, L. Jatsch, S. Hasse, K. Weltmann, K. Masur, T. von Woedtke, Risk assessment of a cold argon plasma jet in respect to its mutagenicity, Mutat. Res. 798 (2016) 029518.

[61] S. Kluge, S. Bekeschus, C. Bender, H. Benkhai, A. Sckell, H. Below, M. Stope, A. Kramer, Investigating the mutagenicity of a cold argon-plasma jet in HET-MN model, PLoS One 11 (2016) e0160667. 